\title{
DETERMINACIÓN DE LA PRODUCCIÓN DE FOLLAJE VERDE DE LA Acacia decurrens EN EL PRIMER AÑO DE SIEMBRA ${ }^{1}$
}

\author{
JANCY DARLY FLÓREZ-OCHOA², ÁLVARO LÓPEZ-DUEÑEZ³, ALEJANDRO \\ RENDÓN-VÁSQUEZ ${ }^{2}$, JUAN MANUEL PÉREZ-ZAPATA ${ }^{2}$ \\ jancydarly@yahoo.com.ar
}

Manizales, 2009-11-19 (Rev. 2010-05-14)

\section{RESUMEN}

La determinación de la producción de follaje verde en el primer año de siembra de la Acacia decurrens se realizó en la finca La Ramada, Quindío, a $4^{\circ} 31^{\prime} 41^{\prime \prime}$ de latitud norte y $75^{\circ} 32^{\prime} 41^{\prime \prime}$ de longitud oeste, con una temperatura promedio de 16 ${ }^{\circ} \mathrm{C}$. Las plantas fueron establecidas con un mes de edad, en surcos paralelos a la pendiente, podadas al alcanzar $1,8 \mathrm{~m}$ de altura y defoliadas manualmente simulando el ramoneo que realiza el ganado. Las densidades de siembra fueron: alta, media y baja: 1664, 832 y 416 acacias/hectárea, respectivamente; se realizaron defoliaciones por periodos a los 6, 9 y 12 meses de siembra. Las variables a medir fueron: peso en gramos de follaje verde por árbol e incremento en gramos de follaje verde/árbol/día. Todos los datos fueron analizados por ANOVA. No fue encontrada diferencia significativa $(P>0,05)$ entre las variables analizadas al estudiar las diferentes densidades de siembra. Se evidenció diferencia significativa $(P<0,05)$ entre periodos de defoliación, al analizar la variable de incremento en gramos de follaje verde por día, esto indica, que la producción de gramos de follaje verde fue mejor en el tercer periodo. La producción de follaje verde de la acacia en el primer año no se ve afectada por las diferentes densidades de siembra y hay un incremento de la producción de follaje verde a medida que las acacias incrementan su edad.

\section{PALABRAS CLAVE:}

Defoliaciones, densidades, forrajera, periodos.

\section{PRODUCTION OF FOLIAGE AT Acacia decurrens IN THE FIRST PLANTING YEAR}

\section{ABSTRACT}

Green foliage production of Acacia decurrens during the first planting year was determined in La Ramada farm, Quindío, located at $4^{\circ} 31^{\prime} 41^{\prime}$ north latitude and $75^{\circ} 32^{\prime} 41^{\prime \prime}$ west longitude, with an average temperature of $16{ }^{\circ} \mathrm{C}$. The planting age was one month, in rows parallel to the slope, pruning at $1,5 \mathrm{~m}$ high, and manual defoliation simulating cattle grazing. The planting densities were high, medium, and low: 1664, 832 and 416 acacias/hectare, respectively; the defoliation frequency was at 6,9 and 12 months of planting. The variables measured were: foliage production grams/tree and grams/tree/day of foliage increment. All data were analyzed by ANOVA. In this trial, the planting densities were not significant $(P>0.05)$; however, between defoliation periods the grams/tree/day of foliage increment were significant $(P<0.05)$, because a better production was seen in the third defoliation period. Acacia foliage production in the first planting year was not affected by the three different densities, and the foliage production increment improves with age. 
KEY WORDS: Defoliations, densities, forage, periods.

\section{INTRODUCCIÓN}

En Latinoamérica la actividad ganadera intensiva ha ocasionado el deterioro de los suelos debido a la compactación de la tierra producida por el ganado, y a la introducción de especies exóticas forrajeras que sustituyeron la vegetación nativa (Ríos, Gómez \& Quiceno, 2000; Arranz et al., 2003). Las diferentes especies exóticas forrajeras exigen fertilizantes y agroquímicos para su sostenimiento (Medina, Orozco \& Diez, 2008), lo que empeora el problema ambiental y aumenta los costos de producción (Giraldo \& Bolívar, s.f.).

Una solución a esta problemática es la inclusión de especies arbóreas forrajeras en los potreros, debido a que contribuyen a corregir los problemas de degradación de suelos e incrementan la producción ganadera (Montagnini et al., 1992).

La Acacia decurrens es una de las especies arbóreas que han sido utilizadas para corregir el problema del deterioro de los suelos de clima frío (Alarcón, Lozano \& Chaparro, 1997), debido a su excelente crecimiento en los primeros meses de edad (Giraldo, 1995; Londoño et al., s.f.) y a su adaptación en suelos pobres en nitrógeno, pues tiene gran capacidad de bombear nutrientes desde las profundidades del suelo (Montagnini et al., 1992), puede crecer en altas densidades de siembra hasta $0,60 \mathrm{~cm} /$ día, incrementa el número de ramas al ser podada y produce $1147 \mathrm{~kg} / \mathrm{ha} / \mathrm{año}$ de biomasa comestible a los 15 meses de edad (Quiceno \& Medina, 2006), además la acacia es una fuente nutricional importante para el ganado por su alto contenido de proteína (16,74\%), bajo contenido de humedad (59,93\%) (Cuesta \& Carvajal, s.f.) y bajo contenido de pared celular (Giraldo \& Bolívar, s.f.).

Los objetivos del presente estudio fueron determinar la producción de follaje verde y su incremento según las densidades de siembra y los periodos de defoliación.

\section{MATERIALES Y MÉTODOS}

\section{Localización}

Las observaciones se realizaron en el departamento del Quindío en la finca La Ramada, en la vereda Camino Nacional del municipio de Salento; ubicada a $75^{\circ}$ 32 ' $41^{\prime \prime}$ de longitud oeste y $4^{\circ} 31^{\prime}$ '41" de latitud norte, a una altitud de 2450 $\mathrm{msnm}$, su temperatura promedio es de $16^{\circ} \mathrm{C}$. El pasto predominante es el kikuyo (Pennisetum clandestinum).

\section{Establecimiento}

Para realizar el experimento se seleccionaron tres hectáreas, con una pendiente promedio del $50 \%$. Los árboles se establecieron con un mes de edad, en surcos paralelos a la pendiente. Las acacias fueron podadas al alcanzar 1,8 $\mathrm{m}$ de altura, buscando estimular el crecimiento de nuevas ramas. 


\section{Tratamiento}

Se establecieron tres densidades de siembra (alta, media y baja) de la siguiente forma: la densidad alta con 1664 acacias/ha, a una distancia entre acacias de $0,55 \mathrm{~m}$ y entre surcos de $11 \mathrm{~m}$; la densidad media con 832 acacias/ha, a una distancia entre acacias de 1,5 $\mathrm{m}$ y entre surcos de $8 \mathrm{~m}$; y la densidad baja de 416 acacias/ha, a una distancia entre acacias de $3 \mathrm{~m}$ y entre surcos de $8 \mathrm{~m}$.

Los periodos de defoliación se realizaron a los 6, 9 y 12 meses de siembra. Las variables a medir fueron: el follaje verde por árbol, que se determinó por defoliación manual completa, cada muestra se pesó en una balanza electrónica y los resultados se expresaron como gramos de follaje verde por árbol (FVA); e incremento de follaje verde gramos/día (IFVAD), la cual se calculó a partir del peso total del follaje verde, dividido por el número de días transcurridos entre la siembra y la primera defoliación; y entre defoliaciones.

\section{Diseño experimental}

Se realizó un diseño completamente al azar con tres réplicas para cada uno de los tratamientos. Tres densidades de siembra con tres réplicas y tres periodos de defoliación.

Como unidad experimental se seleccionaron 25 acacias escogidas por muestreo aleatorio simple para cada densidad de siembra.

\section{Análisis estadístico}

El análisis de todos los datos se realizó mediante el uso de SAS (Statistical Analysis System) usando el procedimiento de ANOVA; la comparación de medias se realizó mediante la prueba de Tukey con un nivel de confianza del 95\%.

\section{RESULTADOS Y DISCUSIÓN}

Se encontró que en el primer año de establecido el ensayo, no hubo diferencias significativas $(P>0,05)$ en las tres densidades de siembra (Tabla 1$)$; sin embargo, se observa un aumento de gramos/árbol/día en la densidad \# 1 (0,42 g/árbol/día). Esto concuerda con lo observado por Quinceno y Medina (2006) quienes observaron que una densidad alta de siembra (1664 acacias/ha) produce mayor cantidad de follaje verde comparado con una de baja densidad.

Tabla 1. Promedio del crecimiento según densidad de siembra - "La Ramada".

\begin{tabular}{|c|c|c|c|c|}
\hline Densidad de siembra: & $\# 1$ & $\neq 2$ & $=3$ & $\mathrm{P}<$ \\
\hline Follaje verde (FVA), g/árbol & 41,8 & 39,3 & 34,2 & 0,148 \\
\hline Incremento de follaje verde (IFVAD), g árbol dia & 0,42 & 0,30 & 0,30 & 0,584 \\
\hline
\end{tabular}

Se encontró diferencias significativas $(P<0,05)$ entre periodos de defoliación en la variable incremento de follaje verde gramos/árbol/día (Tabla 2 ), la cual muestra claramente que la producción a los 12 meses fue superior (0,60 g/árbol/día) que la defoliación a los 9 meses (0,29 g/árbol/día) y a los 6 meses (0,19 g/árbol/día), 
esto concuerda nuevamente con lo citado por Quiceno y Medina (2006) donde mencionan que las acacias producen mayor cantidad de biomasa comestible a medida que aumentan su edad.

Tabla 2. Promedio del crecimiento según periodo de defoliación - "La Ramada".

\begin{tabular}{lcccc}
\hline \multicolumn{1}{c}{ Periodo de defoliación: } & $\# 1$ & $\# 2$ & $\neq 3$ & $\mathrm{P}<$ \\
\hline $\begin{array}{l}\text { Follaje verdeF (VA), g/árbol } \\
\text { Incremento de follaje verde (IFVAD), }\end{array}$ & $41,5 \mathrm{a}$ & $25,6 \mathrm{~b}$ & $48,3 \mathrm{a}$ & 0,001 \\
$\mathrm{~g} /$ árbol/dia & $0,19 \mathrm{~b}$ & $0,29 \mathrm{~b}$ & $0,60 \mathrm{a}$ & 0,001
\end{tabular}

Letras diferentes en una misma fila indican diferencias significativas $(\mathrm{P}<0,5)$ por la prueba de Tukey.

En previos estudio se ha encontrado que la acacia tiene un follaje muy denso, es resistente al maltrato y a las podas continuas (Pérez, 1990) al igual que su crecimiento precoz para permitir el ingreso de los animales cuando alcanzan los $2 \mathrm{~m}$ (Borel \& Romero apud Giraldo, 2000). Esto concuerda con la necesidad de podar las plantas en este ensayo a los 9 meses de siembra, pues ya superaban los $2 \mathrm{~m}$ de altura a pesar de la defoliación realizada a los 6 meses.

\section{CONCLUSIONES}

Las diferentes densidades de siembra no influyen en la producción de follaje verde de la acacia durante el primer año de siembra, por el contrario, sí se demuestra un incremento de la producción de follaje verde a medida que las acacias incrementan su edad (31g más después de la segunda defoliación).

Se recomienda el ingreso de los animales al potrero sembrado con acacias con 10 meses de edad, debido a que su producción y resistencia lo permiten.

\section{BIBLIOGRAFÍA}

- Alarcón, Edna Patricia; Lozano, Amanda y Chaparro, Héctor. (1997). Caracterización fenotípica de aislamientos rizobianos de acacia (Acacia sp.) y Retamo (Teline monpessulana). Revista Colombiana de Química, Vol. 26, No. 2 [en línea]: Santafé de Bogotá: Corporación Autónoma Regional de Cundinamarca CAR. Disponible en: http://www.icfes.gov.co/revistas/recolqui/972602/97260203abs.htm

- Arranz, C, Galantini J, Iglesias J, et al. (2003). Sistema de Labranza: Efecto del Pastoreo Animal sobre la distribución del tamaño de Poros. Instituto Nacional de Tecnología Agropecuaria. Sitio argentino de producción animal. Obtenido el 5/10/09, desde http://docs.google.com/gview?a=v\&q=cache:xockdEQvpHIJ:www.pro duccion-animal.com.ar/suelosganaderos/56-porosidad.pdf+ganado+ $\mathrm{y}+$ erosi\%C3\%B3n+macroporos\&hl=es\&gl=co\&sig=AFQjCNFsy0tSdBVmV gv1b T kyrglLiPRxvA

- $\quad$ Borel, R.; Romero, F. (1991). On farm research in a silvopastoral project: a case study. Agroforestery Systems, 15, 245-257. Citado por Giraldo V., Luis A. (2000). Sistemas silvopastoriles, alternativa sostenible para la ganadería colombiana. Medellín: Universidad Nacional de Colombia sede Medellín. 
- Cuesta Peralta, Aurora y Carvajal Salcedo, Teresa. (s.f.). Evaluación nutricional de 4 especie arbóreas de clima frío para ser usado en la alimentación animal. Corporación Universitaria de Ciencias Aplicadas y Ambientales. Bogota, Colombia .

- Giraldo V., Luis A. (1995, Nov-Dic). Casos exitosos y su potencial en Colombia. En Seminario Internacional Sistemas Silvopastoriles. Ministerio de Agricultura y Desarrollo Rural, Santafé de Bogotá, La Dorada y Santa Marta. Citado por Giraldo V., Luis A. y Bolívar V., Diana M. (s.f.). Evaluación de un sistema silvopastoril de Acacia decurrens asociada con pasto kikuyo Pennisetum clandestinum, en clima frío de Colombia. Medellín: Universidad Nacional de Colombia. Obtenido el 10 enero de 2009, desde http://www.cipav.org.co/redagrofor/memorias99/GiraldoA.htm (2000). Sistemas silvopastoriles, alternativa sostenible para la ganadería colombiana. Medellín: Universidad Nacional de Colombia sede Medellín.

- Giraldo V., Luis A. y Bolívar V., Diana M. (s.f.). Evaluación de un sistema silvopastoril de Acacia decurrens asociada con pasto kikuyo Pennisetum clandestinum en clima frío de Colombia. Medellín: Universidad Nacional de Colombia. Obtenido el 10 enero de 2009, desde http://wwww.cipav.org.co/redagrofor/memorias99/GiraldoA.htm

- Londoño L. Mauricio, Velázquez V. Raúl y Giraldo V. Luis Alfonso. (s.f.). Uso del follaje de la arbórea Acacia Negra, Acacia decurrens como suplemento para el levante de terneras. Medellín: Universidad Nacional de Colombia. Obtenido el 08/10/2009, desde http://www.cipav.org.co/redagrofor/memorias99/LondonoM.htm

- Medina M.; Orozco H.; Diez M. C. (2008). Establecimiento de un Sistema Silvopastoril mediante las especies Alnus acuminata H.B.K. y Acacia decurrens Willd y respuesta al empleo de organismos rizósfericos en San Pedro (Antioquia). Livestock Research Development, v. 20 n. 1. Obtenido el 30/09/2009, desde http://www.Irrd.org/Irrd20/1/medi20007.htm

- Montagnini, Florencia et. al. (1992). Sistemas agroforestales, principios y aplicaciones en los trópicos. Organización de Estudios Tropicales, Costa Rica. s.I.: s.n. p. 17-19.

- Pérez, E. (1990). Plantas útiles de Colombia. Medellín: Víctor Hugo. p. 487-488.

- Ríos, Walter; Gómez, Fernando y Quiceno, Jaime. (2000). Enfoque silvopastoril de tres susbsistemas bovinos de doble propósito en un contexto micropredial andino. Módulo VIII. Caracterización del los sistemas de producción agroprecuarios en el alto de Caldas. Manizales: Litoas. ISBN 958-96720-5-1.

- Quiceno, Jaime y Medina M. (2006). La Acacia decurrens Will fuente potencial de biomasa nutritiva para la ganadería del trópico de altura. Livestock research for rural development, v. 18 n. 12. Obtenido el 30/09/2009, desde http://www.Irrd.org/Irrd18/12/quic18166.htm

\section{Financiado por CORPOICA.}

2. Maestría en Ciencias Veterinarias, Universidad de Caldas, Manizales, Colombia.

3.Programa de Medicina Veterinaria y Zootecnia, Universidad de Caldas, Manizales, Colombia. 